\title{
Assessing the impact of temporary housing sites on urban socio-spatial performance: the case of the Central Italy earthquake
}

\author{
Camilla Pezzica $^{1,2}$ [0000-0002-0512-7591] Chiara Chioni $^{1 \mathrm{~b}}{ }^{[0000-0002-8296-3091]}$, Valerio Cutini ${ }^{1 \mathrm{c}}$ \\ [0000-0003-4065-6226], Clarice Bleil de Souza ${ }^{2 b}$ [0000-0001-7823-1202] \\ ${ }^{1}$ Department of Energy, Systems Territory and Construction Engineering, University of Pisa, \\ Largo Lucio Lazzarino, 56122, Italy \\ ${ }^{2}$ Welsh School of Architecture, Cardiff University, Bute building, King Edward VII Avenue, \\ CF10 3NB, Cardiff, UK \\ ${ }^{1,2}$ Pezzicacecardiff.ac.uk, ${ }^{1 b}$ C.chioni@studenti.unipi.it, \\ ${ }^{1 \mathrm{c}}$ valerio.cutini@ing.unipi.it, ${ }^{2 \mathrm{~b} B l e i l d e s o u z a c @ c a r d i f f . a c . u k}$
}

\begin{abstract}
This paper advocates a performance-based approach to the planning of temporary housing sites after sudden urban disasters. A "functionally graded" configurational analysis method is used to assess, quantitatively and qualitatively, the socio-spatial impact of government-led housing assistance provision across the regional, urban and neighbourhood scales. To highlight the different outcomes achieved in different urban contexts by apparently similar housing recovery plans, a diachronic comparative study of four epicentral historic towns hit by the 2016-2017 Central Italy earthquakes is performed. The research analyses the configurational properties of these settlements at four critical points in time: before the disaster; right after it (emergency phase); during disaster recovery; after the reconstruction is completed. This paper builds on previous research on rapid urban modelling and economic spatial analysis workflows to respond to potential implementation challenges, which include time constraints and geo-data availability issues after disasters. By using a real case scenario, this study seeks to demonstrate the potential benefits of adopting the proposed multidimensional spatial analysis method to foster the delivery of integrated housing recovery solutions, which contribute to sustainable urban development These encompass informing, timely updating, and coordinating strategic, management, and operational decisions related to the design and planning of temporary housing sites.
\end{abstract}

Keywords: Temporary Housing, Disaster Recovery, Multiscale Spatial Modelling, Space Syntax, Design Decision-making, Sustainable Urban Development

\section{Introduction}

\subsection{Temporary housing sites}

Temporary Housing (TH) sites are commonly built by governments and NGOs, after major and sudden urban disasters, to house the homeless population for the duration of 
the reconstruction works, if any, once the immediate emergency phase has ended. These solutions can be offered as an alternative to cash grants for housing rental and are similarly meant to allow restoring normal housing and life routines, which requires having access to suitable services and infrastructures as well as to adequate housing and neighbourhood conditions. Concentrating the construction of temporary housing on public sites is common in cities and towns where, possibly due to urban density issues, plots lack the requirements to safely implement transitional housing solutions on private land. The construction of TH sites is often justified by an intention to preserve community bonds by maintaining affected individuals and families in close physical proximity. However, their effectiveness and convenience have been seriously questioned [1-3], due to the negative impact that they can have, sometimes unexpectedly, on the overall disaster recovery process. In certain cases, the implementations of inadequate TH solutions has, in fact, undermined the possibility to improve on the pre-disaster vulnerability conditions, which has negatively affected urban development with respect to economic, social and environmental sustainability goals [4].

Certain key decisions concerning their location, number, dimension, density, and layout need to be taken soon after a disaster strikes, often on the base of limited official information, with or without the support of a strategic plan. Even when present, the strategic plan needs to be promptly updated to better respond to contextual changes and dynamic legislation adjustments, which may be required for different reasons (e.g., aftershocks, governance based on ad hoc regulations, technical practicalities, etc.). As a matter of fact, because of contextual differences present across a large disaster-affected area, requirements may change in different urban contexts and adopting a homogeneous approach in planning TH sites can therefore not be appropriate. Indeed, there is no universal recipe for planning and designing TH sites as, when resorting to a non-diversified housing recovery strategy, dissimilar socio-spatial outcomes can be achieved in apparently similar settings.

Assuming that the number of people in need of this type of housing assistance is known, choosing a TH site location involves either selecting a higher number of $\mathrm{TH}$ areas closer to the original settlement or a smaller number of sites further away [5]. Although strategic in nature, this decision is often constrained by considerations of site capacity, availability of infrastructures and services, cost of land and potential land ownership issues, and often requires operating difficult trade-offs. Under certain conditions, the location and layout of TH sites, can seriously affect the spatial performance of a recovering city and, in some extreme cases, trigger the decentralization of a settlement [6] by perturbating its inner geography and characteristic accessibility distribution. Additionally, selected housing typologies, construction technologies and materials, should align with a strategic vision to satisfy related durability requirements and allow for subsequent adjustments, such as longer lifespans, densification plans, and incremental housing transitions, if necessary.

Therefore, decisions about TH sites need to be made coherently, in multiple interdependent domains, across the regional, urban, and neighbourhood scales, and should be guided by planning foresight and informed deliberation. To tackle these issues, this 
paper, firstly, proposes a "functionally graded" multiscale configurational analysis method aimed at supporting TH design and planning. Then, it qualitatively tests, in a real disaster scenario, the potential of the proposed method to better inform the assessment of the medium- and long-term impact of TH sites on urban spatial performance.

\subsection{The central Italy earthquake}

Four central Italy regions, 10 province (districts), and 138 comuni (municipalities), scattered around a territory of $8000 \mathrm{~km}^{2}$, were hit by a long series of devastating seismic waves between the $25^{\text {th }}$ of August 2016 and the $18^{\text {th }}$ of January 2017. These events caused the direct and indirect death of hundreds of people, the disruption of the local economy and the destruction of several cultural heritage sites, with material damages estimated at 23 billion and 530 million euros [7]. The territory impacted by the disaster is characterized by the presence of small, rather segregated, historical settlements, scattered across a mountainous area, currently undergoing a process of depopulation and inhabited by an aging population, whose livelihood depends on small local businesses.

By the $22^{\text {nd }}$ of August 2018, a total of 49844 displaced people was provided with some form of housing assistance, and hosted in either prefabricates structures, hotels, rural emergency modules, containers, municipal facilities or in rented accommodations. Of these, 7782 people requested to be housed in prefabricated houses of 40,60 or 80 net square meters, called S.A.E.s, within a total of $228 \mathrm{TH}$ sites [8], (Figure 1).

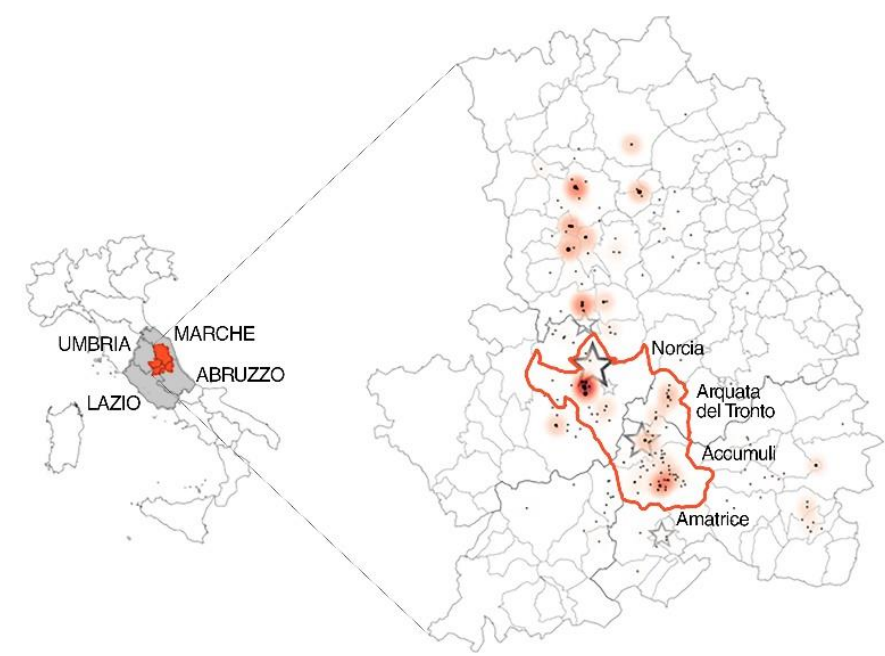

Fig. 1. Location of the disaster affected area in central Italy (which includes portions of Umbria, Abruzzo, Marche and Lazio) and heat map of the number of people hosted in the TH sites. The epicentres of the 2016-2017 earthquakes are marked with stars proportional to their magnitude.

\section{S.A.E.s' procurement and TH sites' construction}


The beginning of the period of emergency management was officially declared by the national authorities in August 2016 and its end was then repeatedly postponed until the end of December 2019. During this time numerous ordinances have been issued by the Italian Civil Protection Department (DPC), the body in charge of assisting the affected population, by monitoring and coordinating relief and housing recovery operations.

The design of the S.A.E.s and their furnishing, as well as the conditions for their delivery and installation, had been pre-arranged as part of a strategic framework agreement for prompt disaster response, targeting the entire Italian territory (divided in North, Centre and South), which was signed in 2015 between the DPC and a few suppliers, such as the CNS (the tender's winner in Central Italy) and Consorzio Stabile Arcale (second in the ranking). The CNS's housing modules are made of steel and wood and were designed to be comfortable in all Italian climates (although this has been repeatedly contested in the media after the disaster), accessible to disabled people, energy efficient, compliant with the Italian seismic regulations and with safety, hygiene and environmental requirements.

According to the tender documentation, it should be possible to combine the TH units, as well as to remove and recover the S.A.E.s, when they are no longer needed. However, even if around $60 \%$ of building components are reusable, their foundation system (consisting of concrete slabs) and urban infrastructure works are hardly reversible, which prevents to easily return the $\mathrm{TH}$ sites on which the units are built, to their initial condition and land use. In fact, several of the affected municipalities have decided to expropriate the land occupied by the TH sites, whenever it was not public already. Moreover, further investments will certainly be required in the near future as the CNS's housing units have an intended first lifecycle of only six years [9]. Despite early statements of intentions, the validity of the hypothesis of the temporariness of these TH plans is further challenged by the actual timescale of the sites' urbanization and housing delivery operations. At the time of writing, almost 4 years after the first quake, the construction works related to TH delivery in central Italy have yet to be totally completed [10].
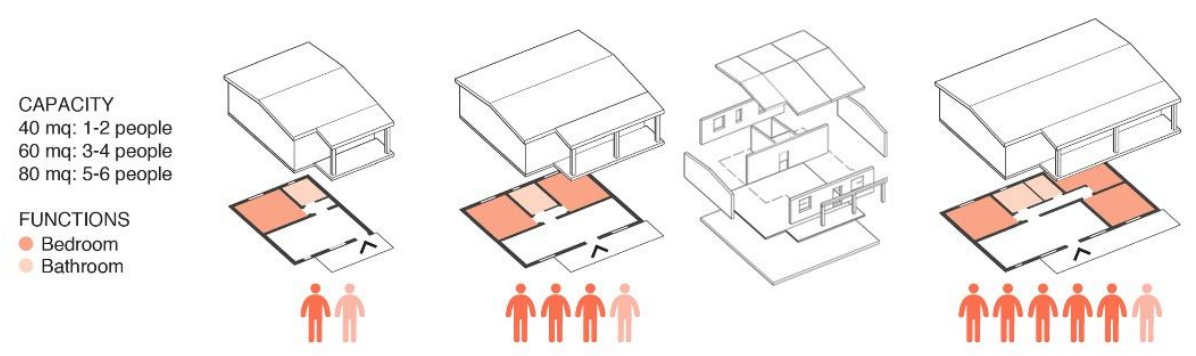

Fig. 2. 2D and 3D schemes of the 3 S.A.E. housing unit types supplied by the CNS.

The ordinance n. 394/2016 identified the four affected regions, namely Umbria, Marche, Lazio, and Abruzzo, as responsible for the construction of the TH sites in their 
administrative areas. The same document established that the candidate sites for locating the TH structures had to be identified by the municipalities, after a quantitative needs' assessment, considerate of non-housing requirements such as schools, churches, hospitals, etc., and later, had to be assessed for approval by the responsible regional administration. As a general strategy the ordinance required the municipalities to prefer public areas over private ones (to avoid delays due to appeals of landowners to the TAR, the Italian regional administrative court) and to contain the number of TH sites, while considering the needs of people. The strategic agreement stated that the executive urbanization projects had to be commissioned to the TH suppliers, after approval of the design of the TH site layout by the relevant municipality. However, it did not consider the need for important site preparation works, including site consolidation and safety interventions to mitigate hydrogeologic and hydraulic risk, and works to attach a TH site to the local service grid if the linking point was beyond its boundaries. This required the introduction of a new directive, which highlighted the importance of making informed choices regarding TH sites' selection early on, due to their likely impact on urbanisation and site preparation costs, which could have hardly been sustained in small TH sites with less than 5 units [11]. The same ministerial circular set also a cap for the cost of urbanization works (of $18000 €$ ), site preparation (7000 $€$ ), and a reference limit of dedicated gross surface area $\left(200 \mathrm{~m}^{2}\right)$ per TH unit. Additionally, it suggested limiting the provision of trees and street furniture in $\mathrm{TH}$ sites.

\subsection{Scope and objectives}

The examples reported in the scientific literature as well as the case of Central Italy confirm that the level of complexity embedded in the task of planning TH sites after sudden urban disasters, requires a focus on urban systems' performance, in line with long-term urban development objectives. Within a context of dynamic changes, lengthy construction works and bureaucratic procedures, such as that described in Section 1.2, it seems crucial to provide humanitarian professionals with instruments that allow a multidimensional understanding of the consequences that morphological transformations have on recovering settlements after a sudden disaster.

Therefore, this study proposes and tests a scenario-based, spatial analysis method, suitable to interrogate aspects of TH sites related to both society and space, and oriented at fostering the implementation of holistic practices in the tactical planning of government-led housing assistance interventions. Specifically, the proposal seeks to augment decision-makers' capacity to align operational planning and design choices, with managerial and strategic decisions concerning TH sites [12]. A statistical correlation analysis between configurational indicators and quantities reflecting the actual planning outcomes in the selected case studies (e.g., distance to POIs, walkability scores, impact of transports etc.) is, however, out of the scope of this paper, as it would inadequately reflect a situation which is still rapidly evolving. Therefore, the validation of the analysis models used in this paper is mainly based on qualitative considerations, supported by official documental evidence, reported news, and in minor part, field observations. 


\section{$2 \quad$ Materials and methods}

In line with other research studies $[13,14]$, this paper suggests adopting a configurational analysis approach based on Space Syntax [15] to look at the problem of locating and designing TH sites. An element of novelty is that this paper uses Space Syntax as an overarching method, which is differently declined to perform the analysis of TH planning scenarios across the macro (regional), meso (urban) and micro (neighbourhood) spatial planning scales, and at multiple significant moments in the disaster management cycle. Performing a "functionally graded" configurational analysis, whose complexity and computational heaviness varies according to the level of information and detail required by the study, simplifies the task of overlapping results of multiple analyses with different theoretical backgrounds and levels of granularity. Furthermore, the multitemporal and multi-scale application of the method, enables disclosing dissimilarities in TH projects, which may otherwise not be obvious nor trivial to identify. The hypothesis is tested through a comparative analysis of four case studies, namely four epicentral historic towns, hit by the 2016-2017 Central Italy earthquakes.

\subsection{Space Syntax approach and metrics}

Space Syntax theory assumes that space in cities (the urban grid) is the enabler of many of the socio-economic interactions that characterise urban life. Despite it being diffused prevalently out of the humanitarian context, its potential in informing and supporting different disaster management tasks has been confirmed by many previous studies. The scientific literature presents examples related to almost all the phases of the disaster management cycle: from disaster prevention and mitigation [16], to emergency response [17], housing relief [18], infrastructure [19] and economic [20] as well as housing recovery [13]. The latter proves that Space Syntax offers novel opportunities for assessing the long-term outcomes of housing recovery plans (i.e., via the quantification of changes in levels of street network resilience and centrality of a given settlement) as it helps understanding the indirect effects of alterations to urban form.

Therefore, this paper exploits different configurational analysis techniques to retrieve quantitative information about the capacity of space to function as intended, so as to enable a nuanced assessment of "what if" situations via a simultaneous study of past, present and possible future scenarios at different spatial scales.

When the focus is on one-dimensional elements (e.g. street networks) it is often recommendable to use an Angular Segment Analysis (ASA) [21]. Two of the most important indices calculated by an ASA are Normalised Angular Integration (NAIN) and Normalised Angular Choice (NACH), which enable to visualise the to-movement and through-movement patterns generated by an urban grid, respectively. NAIN and NACH can be calculated considering either the entire network system (global analysis, Rn) or just a part of it (local analysis, R3). Past research has found correlations between these metrics and phenomena such as pedestrian movement (NAIN R3), presence of commercial activities (NAIN Rn) and intensity of vehicular flows (NACH Rn). 
To establish a link between the configuration of a settlement and the morphology of its open spaces the focus needs to shift from road segments to two-dimensional elements composing a uniform grid. To study the mutual connections of the grid's units it is necessary to perform a Visual Graph Analysis (VGA), [22]; which allows computing several configurational metrics, among which the Integration Index, the Clustering Coefficient and Connectivity. The first indicates the proximity of each point to the most crowded paths and their level of spatial accessibility, the second measures how much a space can be perceived as a spatial unitary entity, whereas the third shows how many nodes of the grid are in direct visual connection. Thus, performing a VGA provides the means to understand the spatial qualities a TH site layout in terms of its specific capacity to: support social interaction, be visually controllable, encourage mutual awareness of people and even accommodate political activism [23]. Arguably, all of these are aspects which contribute to the resilience of displaced communities.

In this study, the first two metrics (NAIN and NACH), are used in the road network analysis at the regional and urban scales, whereas a small selection of VGA indices is used to analyse the TH sites at the neighbourhood scale.

\subsection{Cross-scale and multitemporal analysis}

In order to effectively support the planning of $\mathrm{TH}$ sites the analysis method must be flexible enough to accommodate the non-procedural aspects of the design process, thus allowing jumping across scales, without a fixed direction of flow, to iteratively refine the definition of, and assess the response to a design problem. It is suggested that dependencies exist between scales and that decisions made at one level will inevitably constraint those made at the others. Therefore, being able to understand the problem at various scales, opens doors for conflicts' resolution through design and planning innovation or, at the very least, allows recognising opportunities to save important resources by optimising efforts, through better coordination in decision-making.

Despite this paper presents the proposed method as an ordered sequence of analyses going from the regional to the neighbourhood scale, steps can be omitted (or added) as required, making the methodology open-ended. For instance, the same multi-staged scenario-testing approach can be adopted in the analysis of a TH site at just one scale (e.g., to assess the functioning of a certain layout in time as shown in Section 3). This type of analysis can be understood as a sort of compressed diachronic study, which includes past and present realities, as well as alternative future scenarios.

Due to their relevance for the objectives of this paper, the selected time steps are:

- T1: corresponding to the pre-earthquake situation.

- T2: immediate aftermath of the disaster, characterising the emergency period when access to the dangerous areas at risk of further damage is denied to the lay public.

- T3: post-earthquake situation, characterising the recovery stage, in which some areas (red zones) are still inaccessible and TH sites are built.

- T4: future scenarios after a reconstruction "as it was, where it was" and with no red zones. 
If the analysis considers TH sites to be still present in the T4 scenario, it can assess the impact of their permanency on the spatial geography of a settlement, and help generating possible planning alternatives or regenerative design proposals [24].

Operationally, this paper builds on previous research on rapid configurational analysis workflows using Open Street Map (OSM) data [25] to better respond to potential implementation issues concerning time constraints, geo-data homogeneity across different administrative boundaries and its availability after sudden disasters. To build the T3 and T4 scenarios it was required to gather all the TH site layouts from the municipalities websites and then manually retrace the road centre lines missing in the OSM reference drawings using ${ }^{\circledR}$ Autocad. The resulting .dxf files where put in the correct reference system before performing the ASA and VGA analyses in DepthmapX. Finally, results were exported in QGIS for further elaboration. This work was undergone by the research intern, in preparation to a design research project [26] .

Section 3 shows how the analysis has been coordinated in practice across scales and illustrates the results obtained in the case of the Central Italy earthquake.

\section{Results}

\section{Regional scale}

The analysis at the regional scale was conducted after querying the 2018 OSM database, to retrieve the required Road Centre Lines (RCL) data, representing the streets accessible to both people and vehicles. The map of the disaster-affected region in Figure 3 includes the streets, which have been temporarily closed soon after the earthquake.
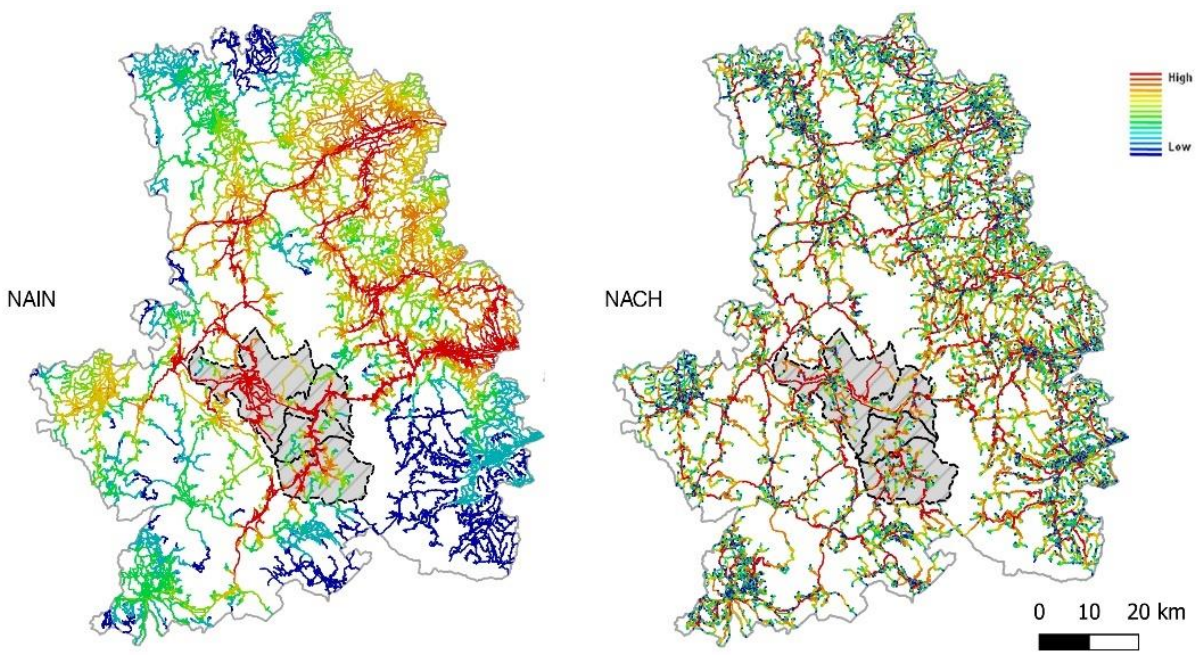

Fig. 3. From the left to the right: NAIN (a) and NACH (b) of the OSM drive network. At the centre, highlighted in grey, the territory of the 4 municipalities analysed in the comparative study. 
High values of NAIN (to-movement, corresponding to the red lines in Figure 3a) highlight the most accessible and attractive locations of the disaster-impacted region. High values of NACH (through-movement, corresponding to the red lines in Figure 3b) highlight the streets hosting most of the transports' flow across the disaster-affected region, that is the regional foreground traffic network.

Overall, the results confirm the outcomes of the 2016 ISTAT (Italian National Institute of Statistics) study, done in the same area [27], which describes the territory as characterised by multiple small urban centralities which are rather difficult to reach and whose livelihood depends on a system of local businesses. Additionally, the analysis offers a clear representation of the most and least accessible/segregated locations of the network and highlights the layers of weaker and stronger connections that mark the territory regionally: in the map, NAIN evidences the most important centres while $\mathrm{NACH}$ how they are connected to the others.

\section{Urban Scale}

Figures 3 and 4 show, with different resolutions, the four neighbouring municipalities that were selected for this study, namely Arquata del Tronto (in Marche), Norcia (in Umbria), Amatrice and Accumoli (in Lazio).

These settlements were chosen considering their proximity to the earthquakes' epicentres. They have suffered the greatest damage, with the consequent displacement of hundreds of people, and host the largest number of $\mathrm{TH}$ sites in the region, due to the high devastation caused by the disaster in the surroundings of these towns.

In line with the national political strategic vision, in all four cases, the TH sites were built close to the destroyed settlements. Probably due to geographic constraints, the capacity of these TH sites does not generally exceed a hundred units, except for a few sites in Norcia. This context sets the conditions for the creation of a distributed system of small TH settlements, scattered around the main routes, with two different types of arrangements: a linear distribution in continuity with the existent urban fabric (letters a in Fig. 4) and a nucleated distribution around the historic core (letters b in Fig. 4).

In Figure 5 the configuration of their street networks has been comparatively analysed at the four points in time described in Section 2.1 (T1-T4) to examine differences in terms of short and long-term impact of TH plans on their urban spatial functioning.

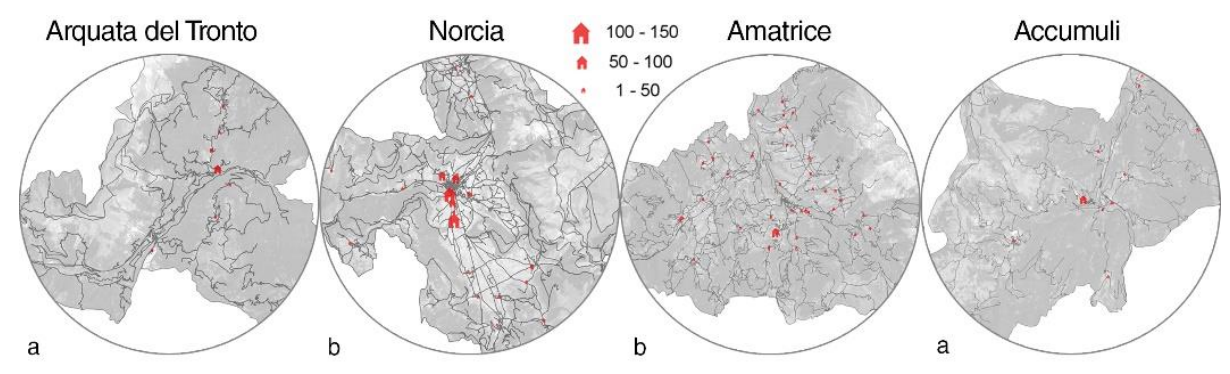

Fig. 4. Location and capacity of the TH sites in Arquata del Tronto, Norcia, Amatrice, Accumuli. 


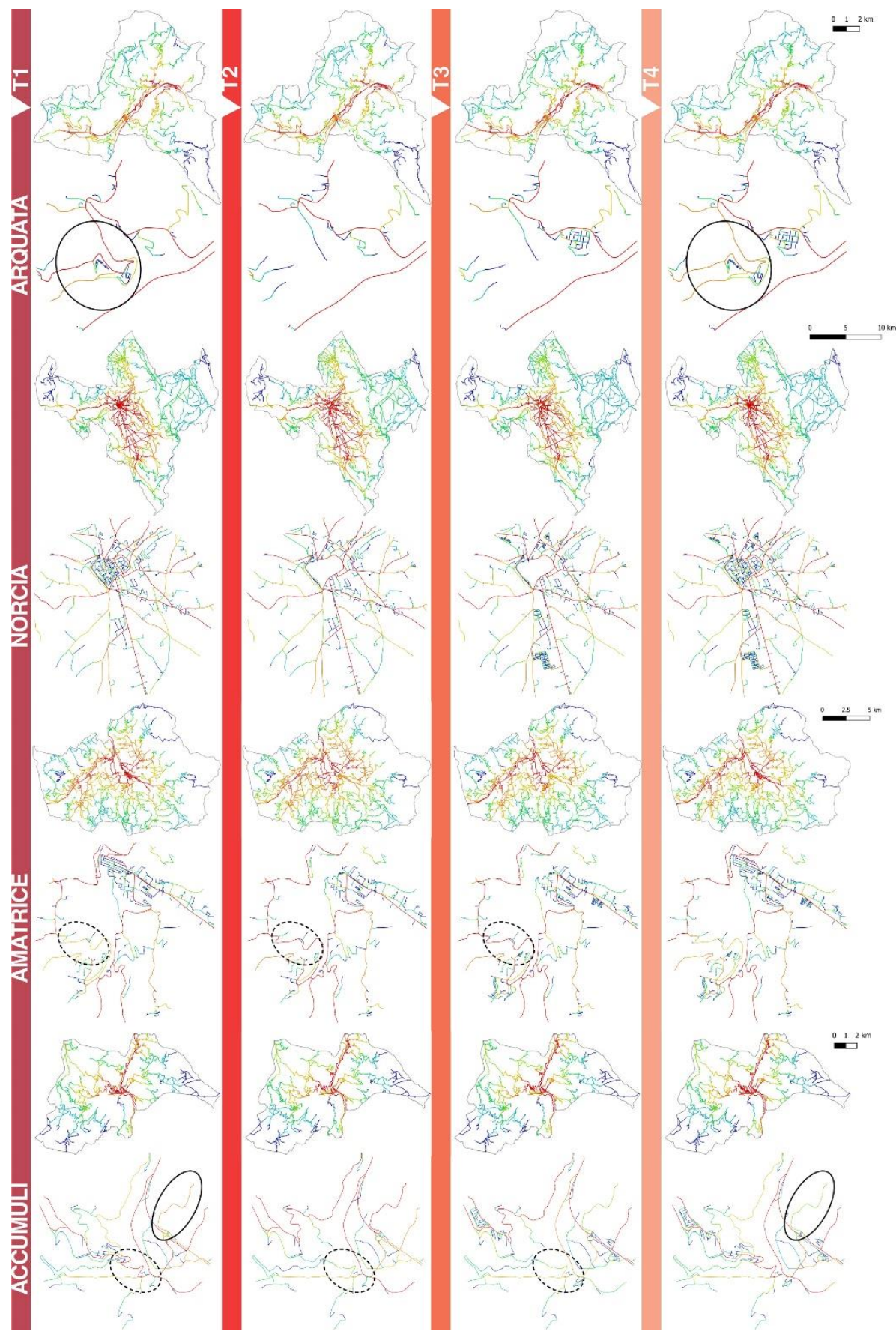

Fig. 5. Comparative ASA analysis T1-T4. NAIN (in the full maps) and NACH (in the zooms). 
Specifically, Figure 5 shows the multitemporal distribution of NAIN and NACH in the considered cases, which is displayed using the same colour gradient adopted in the analysis at the regional scale (Figure 3), with red corresponding to high values and blue to low values of the corresponding configurational indices.

The analysis of the four towns at T1 highlights that, despite these being all small historic centres developed in the same mountainous area in early Roman times (except for Accumuli which was built in the XII century), the functioning logic of their urban grids differed substantially from each other since before the disaster. For example, it is possible to observe that Norcia and Amatrice have grown more densely and organically around their centres, while Accumuli and Arquata del Tronto have had a more linear development, along their main access roads. This is reflected in the distributed nature of centrality values in the former systems versus the polarised character of the latter.

The earthquake destroyed all the four historic areas, causing the closure of the four town centres for safety and reconstruction purposes: a situation studied in the T2 analysis. Here, the maps show, perhaps not surprisingly, that this partial network closure had a negligible impact on the functioning of the remaining parts of Norcia, which presented a modular "spokes and hubs" structure. Contrarily, Amatrice suffered an important loss of centrality and, although less important, so did Accumuli and Arquata del Tronto. The decrease in centrality of the areas surrounding the original urban core, is further reinforced by the location of the TH sites, built during the disaster recovery phase (T3). Notably, the analysis clearly shows that, Arquata del Tronto will be more significantly affected by the presence of the TH sites than the other towns, should these areas continue to be inhabited in the future (T4). In terms of accessibility, the old centre of Arquata del Tronto will be left behind, while the TH site of Borgol will emerge as the new actual town centre.

This result for Arquata del Tronto confirms the outcomes of a previous study on post disaster recovery and reconstruction processes of small settlements in Italy, which has highlighted the risk of them to trigger an effect of urban decentralisation [6]. However, this study also clarifies why this effect can be far less accentuated in other cases such as Norcia, Amatrice, and notably also Accumuli, which demonstrates the usefulness of adopting the proposed methodology to evaluate housing recovery scenarios. Specifically, the analysis shows that the spatial logic of these three towns will not be majorly affected in the long term by the addition of the new TH sites, even if their physical size is not negligible. Once the reconstruction is completed, it may be possible to smoothly integrate the new temporary settlements in the tissue of the recovered urban system as new neighbourhoods or commercial hubs. On the contrary, in the case of Arquata the new streets of the TH sites are likely to acquire economic value and social desirability, thus competing with the recovered town as duplicate centres, if they are not dismantled.

\section{Neighbourhood scale}

Because of its special interest (see paragraph above), the analysis at the neighbourhood scale has been conducted only in the case of Arquata del Tronto and specifically in the area of Borgol: the most central and biggest TH site of the municipality. Being it the 
new configurational centre of town, Borgol assumes a key social role and value, which justifies an effort to further strengthen its relational qualities through urban design.

Issues related to the human-centred design and regeneration of TH sites' layouts are explored in this section, in light of their relevance with respect to the municipality's declared priorities which include: the socio-economic revitalization of the territory; the morphological and functional redevelopment of the urban system; and the return of the residents to their permanent homes.

According to the 2015 strategic framework for the provision of TH units, their spatial distribution, i.e. the design of the TH site layout, should consider the geometry, topography and orientation of the plot on which they are located and follow bioclimatic principles. The use of passive design strategies to regulate the units' indoor thermo-hygrometric comfort through TH site design was formally encouraged. For instance, it was suggested to include summer shading by green infrastructure, good natural ventilation, and arrange the units so as to reduce heat loss by minimizing the ratio between their external surfaces and volume. In addition to a set of planning constraints, the suppliers were required to present at least two different planovolumetric layout proposals, comprising different housing arrangement schemes (e.g. detached houses, courtyard or terraced housing distribution), and exploring different density and aggregation options in relation to height, while providing suitable external access to all housing units.

Although certainly relevant and informative for a complete assessment of the design of a TH layout against its original objectives, an environmental analysis of the site has been omitted, because out of the scope of this study. Instead, a VGA analysis is used to respond to the current need to investigate properties of space that inspire a sense of ownership through occupation, which are related to the spatial navigation and visual perception of an existing TH site. The Integration Index is used as a proxy for spatial accessibility, while the Clustering Coefficient is used to identify pockets with stable visual characteristics, which would allow a comfortable social interaction. Connectivity allows assessing the visual capacity of these areas whereas Control can be used to identify spaces where people naturally tend to make navigation decisions.

The analysis addresses three points in time, namely T1, T3 and T4 because it assumes that the analysis of T2 would mainly be relevant for deciding the location of the $\mathrm{TH}$ site, which in this case is already known and fixed. T3 corresponds to the present layout configuration, while T4 represents the situation in the hypothetical scenario of conservative reconstruction. Notably, other alternative urban reconstruction scenarios could be comparatively tested, as well as a potential T5 situation in which something changes in the present configuration of the $\mathrm{TH}$ site as part of a future urban regeneration project, as illustrated in greater detail in [24].

When performing a VGA, a distinction can be made between a visual accessibility analysis (i.e. computing a visibility graph constructed at eye level) and a permeability analysis, which is applied at knee level to reflect how people can move in a space. This paper implements the latter, as it prioritises an understanding of movement around the TH site: Figure 6 shows that the spatial permeability of the area surrounding the former playground has changed dramatically after the construction of the TH settlement (T3). 

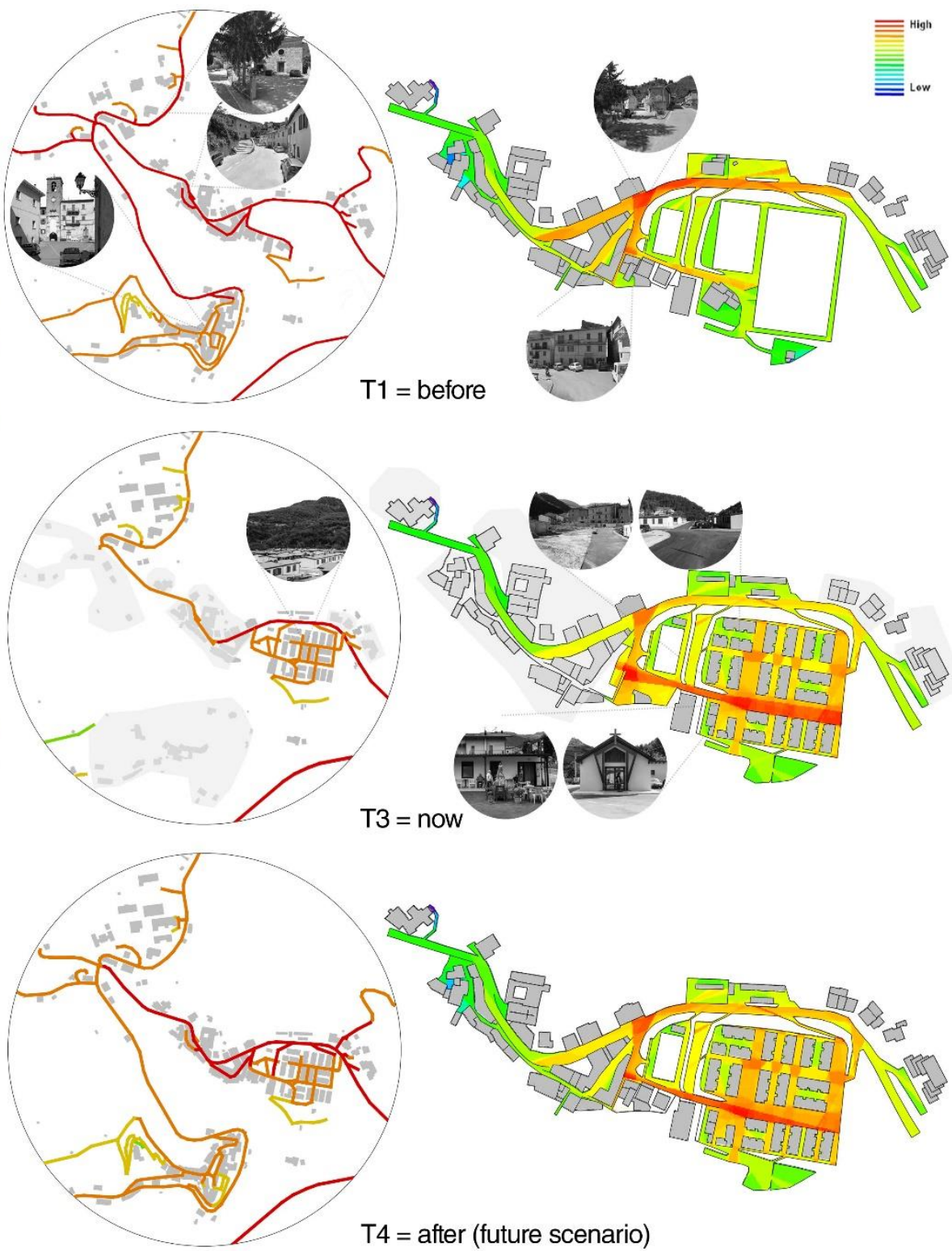

Fig. 6. From left to right: multitemporal ASA (NAIN) of the municipality of Arquata del Tronto and VGA (Integration Index) of the area of Borgol, before the earthquake (T1), today (T3) and in the future reconstruction scenario where everything is built "as it was, where it was" and the TH site is not dismantled (T4). 
The resulting local layout modification has, in fact, generated a number of new open spaces with different morphologies, ranging from the little pockets between the TH units to the larger esplanades in various configurationally central locations. Notably, two perpendicular axes emerge with a high value of centrality/accessibility (corresponding to a high value of the Integration Index), with the horizontal one crossing the temporary village from side to side. Figure 6 indicates that after the completion of the reconstruction works (T4), if no other change applies, the new road axes will maintain a high configurational importance. This result is confirmed by the distribution of NAIN in the ASA (see zooms in Figure 6), which shows that a continued presence of the TH sites in the future (the analysis includes all those built in the municipality), is likely to redefine the socio-spatial logic and accessibility pattern of Arquata del Tronto, creating the conditions for local economic activities to move out of the historic town centre. The analysis' prediction is substantiated by the current "temporary" relocation of many services in the TH site, and in its proximity along the SP 89 road, (photos in Fig. 6) and by the data gathered by the research intern during a field visit in 2019 [24].

\section{Discussion and conclusion}

The results of this study demonstrate the potential of adopting the configurational analysis as an overarching methodology to support the scenario-based planning and design of spatially performative TH sites. In particular, the proposed "functionally graded" method allowed dealing with different spatial scales at different points in time in a synchronous manner, which could help bridging possible communication gaps between decision-makers and facilitating the sustainable development of $\mathrm{TH}$ sites in the long term; both locally and as part of their territory.

Although conducting an extensive empirical validation of all the analysis models, on the one hand, was hardly feasible, and, on the other hand, out of the scope of this research, it was nonetheless possible to find a partial confirmation of the results obtained through the application of the proposed analysis method, in the initial planning outcomes of the TH programme and in some of the policies implemented by the responsible administrations in response to those. For instance, the interventions mentioned in some documents (e.g., Ocdpc n. 510, 518, 538 and 581 among others), involving the addition of services, public transport modifications and road works in the towns, seem to be oriented in the direction shown by the configurational analysis models.

The outputs obtained in the analysis of the selected case studies have practical implications for future housing recovery planning involving the use of prefabricated housing structures. They indicate that special attention should be paid to the choice of the location, as well as to the specific layout, of TH sites, as both can have an important influence on the social and economic functioning of a recovering settlement. This seems particularly relevant for small towns with a linear road network configuration and a limited number of access routes. Understanding the consequences of building TH plans after disasters appears important even in the unlikely event that all TH sites were eventually brought back to their original status, because of their indirect impact on local 
economic activities. The influence that $\mathrm{TH}$ sites exert on pedestrian and vehicular flows during the transitional phase (see circled segments T1-T3 in Figure 5) can, in fact, last for a potentially very long period, corresponding to the length of reconstruction works. Ultimately, this implies that it is extremely improbable that after a disaster of such a magnitude the post urban geography will correspond exactly to the pre-disaster situation, independently of the actual dismantling of TH sites.

To make the proposed methodology fully operational, future applications should select the most meaningful configurational metrics to answer a specific question, considering the local context. Then, results should be critically interpreted by the experts according to their strategic priorities, acknowledging other non-spatial relevant factors.

Future studies should explore positive synergies between the design of TH units and their spatial arrangement (i.e., the design of the TH site layout), by integrating results of a configurational analysis with those of environmental simulations (e.g., daylighting and wind). This will help designers to respond in a more holistic way to the requirements for bioclimatic solutions, and possibly increase the effectiveness of passive design strategies targeting indoor comfort, with implications for energy efficiency.

\section{References}

[1] D. Contreras, T. Blaschke, M.E. Hodgson, Lack of spatial resilience in a recovery process: Case L'Aquila, Italy, Technol. Forecast. Soc. Change. 121 (2017) 76-88.

[2] C. Johnson, Impacts of prefabricated temporary housing after disasters: 1999 earthquakes in Turkey, Habitat Int. (2007).

[3] E. Wagemann, Need for adaptation: transformation of temporary houses, Disasters. (2017). https://doi.org/10.1111/disa.12228.

[4] D. Alexander, An evaluation of medium-term recovery processes after the 6 April 2009 earthquake in L'Aquila, Central Italy, Environ. Hazards. 12 (2013) 60-73.

[5] S.M.A. Hosseini, O. Pons, A. de la Fuente, A combination of the Knapsack algorithm and MIVES for choosing optimal temporary housing site locations: A case study in Tehran, Int. J. Disaster Risk Reduct. 27 (2018) 265-277..

[6] D. Alexander, Preserving the Identity of Small Settlements during Post-Disaster Reconstruction in Italy, Disasters. 13 (1989) 228-236.

[7] DPC, Terremoto centro Italia: Fondo di Solidarietà dell'Unione Europea, oltre 23 miliardi di euro i costi dell'emergenza e la stima dei danni - Comunicato Stampa, 2017. http://www.protezionecivile.gov.it/media-comunicazione/comunicati-

stampa/dettaglio/-/asset_publisher/default/content/terremoto-centro-italia-fondo-disolidarieta-dell-unione-europea-oltre-23-miliardi-di-euro-i-costi-dell-emergenza-e-lastima-dei-danni (accessed January 17, 2020).

[8] DPC, I numeri del sisma in Centro Italia, 2018.

[9] CNS, Le soluzioni abitative in emergenza | CNS, (2016). https://www.cnsonline.it/lesoluzioni-abitative-in-emergenza-del-consorzio-nazionale-servizi/ (accessed January 17, 2020).

[10] DPC, Terremoto Centro Italia: le Sae-Soluzioni abitative in emergenza - Dettaglio 
dossier, (2019). http://www.protezionecivile.gov.it/mediacomunicazione/dossier/dettaglio/-/asset_publisher/default/content/terremoto-centroitalia-le-sae-soluzioni-abitative-in-emergenza (accessed January 17, 2020).

[11] DPC, Circolare della Presidenza del Consiglio dei Ministri del 16/01/2017, (2017).

[12] C. Pezzica, V. Cutini, C. Bleil De Souza, Mind the gap: state of the art on decisionmaking related to post-disaster housing assistance, (unpublished).

[13] V. Cutini, The city, when it trembles: Earthquake destructions, post-earthquake reconstructions and grid configuration, in: 2013 Int. Sp. Syntax Symp., Sejong University Press, 2013.

[14] A. Carpenter, Disaster resilience and the social fabric of space, in: 9th Int. Sp. Syntax Symp., Seoul, Korea, 2013.

[15] B. Hillier, J. Hanson, The Social Logic of Space, Cambridge University Press, 1984.

[16] N. Srinurak, N. Mishima, A.N. Kakon, Urban morphology and accessibility classification as supportive data for disaster mitigation in Chiang Mai, Thailand, Int. Assoc. Lowl. Technol. 18 (2016) 219-230.

[17] N.I. Mohareb, Emergency evacuation model: accessibility as a starting point, Proc. Inst. Civ. Eng. - Urban Des. Plan. 164 (2011) 215-224.

[18] H.-W. Chang, W.-I. Lee, Decoding network patterns for urban disaster prevention by comparing Neihu district of Taipei and Sumida district of Tokyo, MATEC Web Conf. 169 (2018) 01044. https://doi.org/10.1051/matecconf/201816901044.

[19] V. Cutini, C. Pezzica, Street Network Resilience Put to the Test: The Dramatic Crash of Genoa and Bologna Bridges, Sustainability. 12 (2020) 4706.

[20] G. Penchev, Using Space Syntax For Estimation Of Potential Disaster Indirect Economic Losses in: Comparative Economic Research Volume 19 Issue 5 (2016), Comp. Econ. Res. 19 (2016) 125-142.

[21] A. Turner, From Axial to Road-Centre Lines: A New Representation for Space Syntax and a New Model of Route Choice for Transport Network Analysis, Environ. Plan. B Plan. Des. 34 (2007) 539-555. https://doi.org/10.1068/b32067.

[22] A. Turner, M. Doxa, D. O'Sullivan, A. Penn, From Isovists to Visibility Graphs: A Methodology for the Analysis of Architectural Space, Environ. Plan. B Plan. Des. 28 (2001) 103-121. https://doi.org/10.1068/b2684.

[23] V. Cutini, Lines and squares: towards a configurational approach to the morphology of open spaces, in: Proc. 4th Int. Sp. Syntax Symp., London, 2003: pp. 49.1-49.14.

[24] C. Chioni, C. Pezzica, V. Cutini, C. Bleil de Souza, S. Rusci, Multi-scale configurational approach to the design of public open spaces after urban disasters, in: Proc. 5th Int. Symp. Form. Methods Archit. Adv. Sci. Technol. Innov., Springer Nature, Lisbon, n.d.

[25] C. Pezzica, V. Cutini, C. Bleil De Souza, Rapid configurational analysis using OSM data: towards the use of Space Syntax to orient post-disaster decision making, in: Proceeding 12th Int. Sp. Syntax Symp., Beijing JiaoTong University, Beijing, 2019.

[26] C. Chioni, From Temporariness to Permanence.The case of "Borgo di Arquata" after the 2016 central Italy earthquake, 2019.

[27] ISTAT, Caratteristiche dei territori colpiti dal sisma del 24 agosto 2016, 2016. https://www.istat.it/it/archivio/190370 (accessed January 18, 2020). 